\title{
Trophic Effects of Androgen: Receptor Expression and the Survival of Laryngeal Motor Neurons after Axotomy
}

\author{
Julio Pérez and Darcy B. Kelley \\ Department of Biological Sciences, Columbia University, New York, New York 10027
}

To determine whether changes in androgen receptor (AR) expression are associated with trophic actions of androgens, we have examined the laryngeal motor nucleus $(\mathrm{N}$. IX-X) of Xenopus laevis 1 and 5 months after section of the laryngeal nerve. In situ hybridization was used to recognize cells expressing mRNA for the Xenopus AR and bromodeoxyuridine to assess cell proliferation. In addition, the total number of cells was determined in untreated and dihydrotestosterone (DHT)-treated animals after 5 months of axotomy. After 1 month of axotomy, the number of AR mRNA-expressing cells in N. IX-X is 1.8-fold higher than in the intact side. Androgen upregulates expression of AR mRNA in N. IX-X on both the intact and the axotomized sides, suggesting that the increase is independent of contact with muscle. Neither the axotomy- nor the androgen-induced increase in number of cells expressing AR mRNA is attributable to cell proliferation. Five months after axotomy, both the total number of cells and the number of AR mRNA-expressing cells are severely decreased in the axotomized N. IX-X. DHT treatment mitigates the cell loss in N. IX-X induced by prolonged axotomy; the effect includes maintenance of AR mRNA-expressing cells. Gonadally intact males have more cells in the axotomized N. IX-X than castrated animals, suggesting that androgen acts at physiological levels as a trophic hormone. Axotomy-induced upregulation of AR expression may facilitate the trophic actions of androgens.

Key words: trophic factor; dihydrotestosterone; axotomy; androgen receptor mRNA expression; motor neurons
At early stages of development, naturally occurring or injuryinduced motor neuron death can be prevented by treatment with trophic factors (for review, see Oppenheim et al., 1995; Lewin and Barde, 1996). Trophic factors belong to a number of molecular classes with a range of target cell specificities. In some cases, such as the neurotrophins, an endogenous role in ontogenetic rescue of sympathetic and sensory neurons is well established (LeviMontalcini and Booker, 1960; Ernfors et al., 1994; Conover et al., 1995; Liu et al., 1995). It is not yet clear, however, whether these factors, alone or in combination with others, play an endogenous role in control of motor neuron death (Klein et al., 1993; Lewin and Barde, 1996).

The best established endogenous trophic factors for motor neurons are the androgenic steroids (Breedlove, 1992; Kujawa and Jones, 1995). These circulating hormones, produced primarily by the gonads and the adrenal glands, act within target cells by binding to intracellular receptors, which are ligand-activated transcription factors. Androgen rescues specific populations of motor neurons and their target muscles from both ontogenetic and induced death, and the endogenous action of androgens is responsible for sexually dimorphic neuron and muscle fiber numbers in some neuromuscular systems (Nordeen et al., 1985; Yu, 1989; Tobias et al., 1993). Despite their powerful effects, little is known about the mechanism of action of androgens in preventing motor neuron death.

The androgen receptor (AR) is regulated by a number of

Received May 14, 1996; revised July 30, 1996; accepted Aug. 6, 1996.

This work was supported by National Institutes of Health Grant NS19949 and by a fellowship from the Ministry of Education and Science, Spain (EX95 50691740). We thank Dr. Martha Tobias and Michael Cohen for their useful comments on this manuscript.

Correspondence should be addressed to Dr. Julio Pérez, Department of Biological Sciences, Columbia University, 903 Fairchild, New York, NY 10027.

Copyright (C) 1996 Society for Neuroscience $0270-6474 / 96 / 166625-09 \$ 05.00 / 0$ factors, including exposure to hormone and injury, that also affect cell survival. In bulbospinal neuronopathy in humans (Kennedy's disease), a disease associated with an expanded trinucleotide repeat in the transactivation domain of the AR (La Spada et al., 1991), motor neurons in the brainstem and spinal cord (cell types with high levels of $\mathrm{AR}$ expression) die and muscle wasting is observed (Harding et al., 1982; Ross, 1995). The mutation is associated with decreased affinity for androgen (MacLean et al., 1995). These observations suggest that androgen receptor may play an important role in the trophic functions of androgens.

To determine whether changes in androgen receptor expression are associated with survival after injury, we have examined the vocal neuromuscular system of Xenopus laevis. This experimental model is one of the most strongly androgen-regulated systems in vertebrates (for review, see Kelley, 1996). Both the laryngeal motor neuron (Kelley, 1981; Pérez et al., 1996) and the laryngeal muscle (Kelley et al., 1989; Fischer et al., 1993) express high levels of androgen receptor. We have used this system to explore cell death induced by section of the IX-X nerve in juvenile $X$. laevis, the effects of endogenous and exogenous androgens in maintenance of cell number in N.IX-X, and the expression of AR mRNA in N. IX-X after axotomy.

\section{MATERIALS AND METHODS}

Animals and hormone treatments. Three-month-old postmetamorphic frogs (stage P.M.1 according to Tobias et al., 1991) were anesthetized and gonadectomized (see Tobias et al., 1993). All animal maintenance and surgical procedures conformed to National Institutes of Health requirements. A SILASTIC tube (VST 030065, Dow Corning, Corning, NY) containing $5 \mathrm{mg}$ of $5 \alpha-17 \beta$-ol-3-one androstan (dihydrotestosterone, DHT; Sigma, St. Louis, MO), or an empty tube (untreated) was implanted into the dorsal lymph sac. An additional group of age-matched, non-gonadectomized males did not receive SILASTIC implants. The larynx of all animals was accessed through an incision in the body wall, the right IX-X nerve was separated from the laryngeal muscle and severed, 
and $\sim 1 \mathrm{~cm}$ of the proximal segment was removed. Any nerve stump still attached to the larynx was removed. One or five months after gonadectomy, tube implantation, and denervation, animals were transcardially perfused with $5 \mathrm{ml}$ of $0.6 \% \mathrm{NaCl}$ followed by $10 \mathrm{ml}$ of $4 \%$ paraformaldehyde in $1 \times$ PBS (in mM: $2.6 \mathrm{KCl}, 1.4 \mathrm{KH}_{2} \mathrm{PO}_{4}, 136 \mathrm{NaCl}, 8 \mathrm{Na}_{2} \mathrm{HPO}_{4}$, $\mathrm{pH}$ 7.2). At the time of killing, the larynx was examined for signs of reinnervation; none of the animals had a visible nerve on the axotomized side, whereas all had an intact IX-X nerve on the contralateral side. The brain and anterior spinal cord were removed and post-fixed for $2 \mathrm{hr}$ in fixative followed by $20 \%$ sucrose in $1 \times$ PBS for $4-12 \mathrm{hr}$. Horizontal sections $(20 \mu \mathrm{m})$ of the brain were cut in cryostat, thaw-mounted onto microscope slides (Superfrost, Fisher Scientific, Houston, TX) and stored at $-70^{\circ} \mathrm{C}$.

In situ hybridization. A cloned 495 bp PCR fragment containing the ligand-binding domain of the $X$. laevis AR served as template for in vitro transcription (He et al., 1990; Pérez et al., 1996). Sense and antisense probes were synthesized with either Sp6 or T7 RNA polymerase, respectively, in the presence of digoxigenin-dUTP and primers as described previously (Pérez et al., 1996). The AR probe was purified by chromatography through Nensorb-20 columns (DuPont NEN, Boston, MA) and quantified on dot blots by comparison to a digoxigenin-labeled RNA of known concentration (Boehringer Mannheim, Indianapolis, IN). Sections of the brain were air-dried and post-fixed in $4 \%$ paraformaldehyde for 20 min. Slides were then incubated in proteinase $\mathrm{K}(10 \mu \mathrm{g} / \mathrm{ml})$ in $0.1 \mathrm{M}$ Tris- $\mathrm{HCl}, \mathrm{pH} 7.5,10 \mathrm{~mm}$ EDTA at room temperature for $30 \mathrm{~min}$, followed by $10 \mathrm{~min}$ in $0.25 \%$ acetic acid anhydride in $0.1 \mathrm{M}$ triethanolamine. Sections were dehydrated in a graded series of ethanols and air-dried. The tissue was covered with $2 \mathrm{pg} / \mu \mathrm{l}$ AR probe in hybridization solution ( $50 \%$ formamide, $0.6 \mathrm{M} \mathrm{NaCl}, 0.06 \mathrm{M} \mathrm{Na-citrate,} \mathrm{pH} 7,1 \times$ Denhardt's solution, $0.5 \mathrm{mg} / \mathrm{ml}$ yeast tRNA, $0.2 \mu \mathrm{g} / \mathrm{ml}$ salmon sperm DNA, $10 \%$ dextran sulfate) at $50^{\circ} \mathrm{C}$ overnight. As a control for specificity of hybridization signals, a set of sections was hybridized with $2 \mathrm{pg} / \mu \mathrm{l}$ sense probe. Specificity of the probe was determined previously by nuclease protection assays (Pérez et al., 1996). On the next day, sections were washed with $2 \times \mathrm{SSC}$ and $1 \times \mathrm{SSC}$ for $1 \mathrm{hr}$ each, followed by $0.5 \times \mathrm{SSC}$ for $1 \mathrm{hr}$ at $50^{\circ} \mathrm{C}$ and, finally, with RNase A $(10 \mu \mathrm{g} / \mathrm{ml})$ in RNase buffer $(10$ $\mathrm{mm}$ Tris, $\mathrm{pH} 8.0,1 \mathrm{~mm}$ EDTA, $0.5 \mathrm{M} \mathrm{NaCl}$ ) for $30 \mathrm{~min}$ at $37^{\circ} \mathrm{C}$. Hybridization of the AR probe was detected as described previously (Pérez and Hoyer, 1995).

Horseradish peroxidase (HRP) and bromodeoxyuridine double labeling. Two gonadectomized males and two females were implanted with either an empty SILASTIC tube (untreated) or one filled with DHT as described above. The IX-X nerve was unilaterally sectioned in untreated animals. Every other day, animals were injected intraperitoneally with 5-bromo-2'-deoxyuridine $(0.065 \mathrm{mg} / \mathrm{gm}$ body weight, Boehringer Mannheim) in a $7 \mathrm{~mm} \mathrm{NaOH}, 0.6 \% \mathrm{NaCl}$ solution. After 1 month of treatment, crystals of HRP (Type VI, Sigma) were placed within the laryngeal muscle of DHT-treated animals. Three days later, animals were perfused and $10 \mu \mathrm{m}$ sections of the brain were cut in a cryostat. For HRP detection, sections were processed according to the procedure described by Llewellyn-Smith et al. (1992). HRP produced a brown cytoplasmic precipitate in motor neurons. After washing, sections were processed for bromodeoxyuridine immunohistochemistry. Briefly, sections were incubated in $1 \mathrm{M} \mathrm{HCl}$ at $60^{\circ} \mathrm{C}$ for $30 \mathrm{~min}$ followed by two washes in $1 \times \mathrm{PBS}$, covered with $2 \%$ BSA, $0.3 \%$ Triton X-100 in $1 \times$ PBS for $30 \mathrm{~min}$, and then $6 \mu \mathrm{g} / \mathrm{ml}$ anti-bromodeoxyuridine antibody (Boehringer Mannheim) overnight. On the next day, sections were incubated with 1:200 biotinylated IgG for $30 \mathrm{~min}$ and ABC solution according to manufacturer's specifications (Vector Laboratories, Burlingame, CA). The sections were incubated with $0.05 \%$ solution of $3^{\prime}, 3^{\prime}$-diaminobenzidine in Tris buffer plus $0.01 \% \mathrm{H}_{2} \mathrm{O}_{2}$ for $\sim 10 \mathrm{~min}$, dehydrated, and coverslipped.

Cell quantification and statistical analysis. The number of cells in the intact and axotomized N. IX-X were counted in consecutive horizontal sections at $250 \times$ using a light microscope. The number of cresyl violetstained cells in N. IX-X of untreated juvenile males and females reported in this study is identical to the number of axons in the motor nerve innervating the larynx of juveniles (Robertson et al., 1993); N. IX-X contains all laryngeal motor neurons (Simpson et al., 1986). Counts of cells in N. IX-X of untreated juveniles thus reflect motor neuron numbers. Total number of cells was assessed on cresyl violet-stained sections; every stained cell in $\mathrm{N}$. IX-X with a visible nucleus was counted. AR mRNA-expressing cells were labeled with the digoxigenin AR probe and recognized by blue reaction product in the cytoplasm. The reaction product was absent from the cell nucleus, which appears as an unstained circle or ellipse in the cell cytoplasm (see Fig. $3 B$ ). Only cells with both

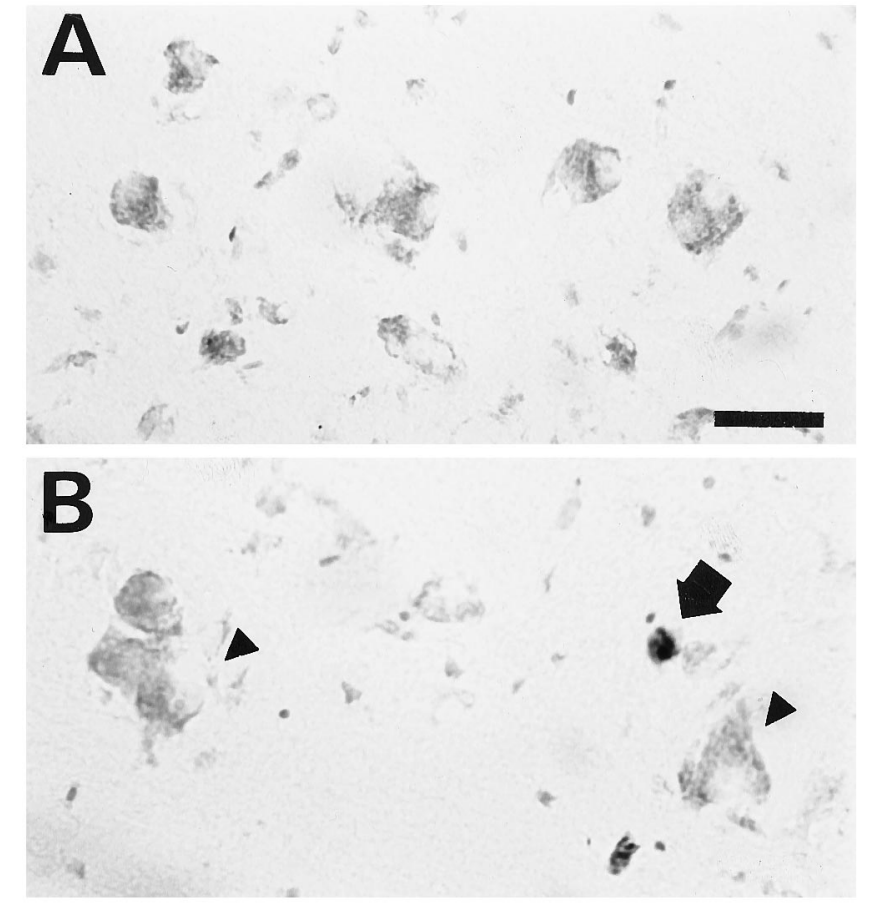

Figure 1. Cell death in N. IX-X after 5 months of axotomy. A, Cresyl violet-stained cells in the intact $\mathrm{N}$. IX-X of a non-gonadectomized male. $B$, In the axotomized N. IX-X, swollen (arrowheads) and pyknotic cells (arrow) are changes associated with prolonged axotomy. Scale bar, $50 \mu \mathrm{m}$.

cytoplasmic labeling and a visible unlabeled nucleus were counted. No stereological correction for sampling errors (Abercrombie, 1946) was applied because the diameter of the cell nucleus did not change with DHT treatment, nor did it differ between intact and axotomized sides. All values given, unless noted otherwise, are mean \pm SEM. Differences in the total number of cells and in the number of AR mRNA-expressing cells were evaluated using a three-way ANOVA with two between-group factors (sex: males vs females; treatment: untreated vs DHT-treated) and one within-group factor (intact vs axotomized). Where appropriate, in each experimental group (males or females), the number of cells in the axotomized N. IX-X was compared to the number of cells in the intact side using a post hoc, paired Student's two-tailed $t$ test. The effects of DHT treatment on the total number of cresyl violet-stained cells or number of AR mRNA-expressing cells were evaluated by comparing animals of the same sex (male or female) and axotomy status (intact or axotomized) across hormone treatments using a post hoc Student's twotailed $t$ test. Number of cells in N. IX-X after 5 months of treatment was assessed by calculating percentage of cells in the right N. IX-X (axotomized) over the left (intact); statistical comparisons between control and DHT-treated animals were made using a two-tailed Student's $t$ test.

\section{RESULTS}

\section{Cell death induced by axotomy in N. IX-X and trophic effects of DHT}

Motor neurons of nucleus IX-X are located in the caudal medulla, adjacent to the inferior reticular formation and just anterior to the spinal cord (Simpson et al., 1986). Five months after axotomy, signs of degeneration were observed on the axotomized, but not on the intact, side of all groups analyzed (Fig. 1 $A, B$ ). On the intact side, cells have a reticulated appearance caused by staining of Nissl substance (cytoplasmic RNA, some of which is associated with polysomes; Fig. $1 A$ ). On the axotomized side, cells are swollen, with dispersed Nissl substance (chromatolysis); some pyknotic cells, densely staining and small in size, are also visible (Fig. 1B). Other cells appear similar to the intact side. The presence of degenerating cells on the axotomized side resembles 

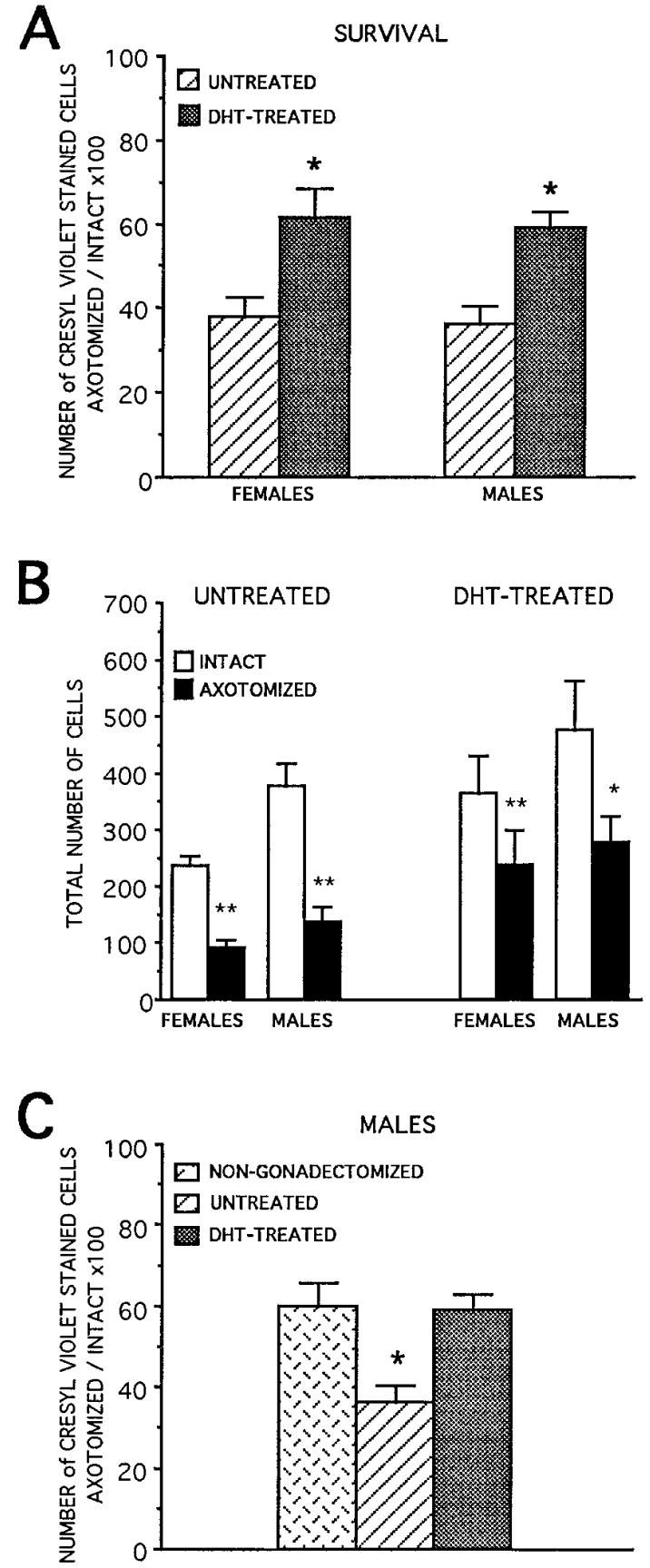

Figure 2. Total number of cells in N. IX-X 5 months after axotomy. $A$, Neuronal survival in N. IX-X of females and males 5 months after axotomy with or without DHT treatment (mean \pm SEM; $n=4$ animals/ group). Significantly $\left({ }^{*} p<0.05\right)$ more cells were found in the axotomized $\mathrm{N}$. IX-X of DHT-treated animals than in untreated gonadectomized animals. $B$, Number of cells (mean \pm SEM; $n=4$ animals/group) in the intact (white) and axotomized (black) N. IX-X of untreated and DHTtreated animals. In all groups, the number of cells in the axotomized $\mathrm{N}$. IX-X was significantly smaller than in the intact side $\left({ }^{*} p<0.05,{ }^{* *} p<\right.$ 0.01). $C$, Significantly more cells survived in the axotomized N. IX-X of non-gonadectomized males and DHT-treated males than in untreated gonadectomized males ( $p<0.05 ; n=4$ animals/group).

that classically observed for injury-induced death of motor neurons. We conclude that the juvenile N. IX-X displays axotomyinduced cell death.

Axotomy reduces the number of cells in N. IX-X, and treatment with DHT increases cell survival (Fig. 2A). In untreated gonadectomized females and males, the survival percentage (ratio of cells counted on the axotomized side to those cells counted on the intact side $\times 100$ ) was $37.9 \pm 4$ and $36.2 \pm 4$, respectively. In DHT-treated females and males, the survival ratio was $61.5 \pm 7$ and $59 \pm 3$, significantly higher than control values ( $p<0.05, n=4$ in all groups). We conclude that exogenous androgen lessens or delays the cell loss induced by prolonged axotomy.

Results of axotomy and DHT treatment in gonadectomized male and female juveniles were analyzed using a three-way ANOVA, which revealed two significant main effects on the total number of cresyl violet-stained cells in N. IX-X (Fig. 2B): DHT treatment $\left(F_{(1)}=6.9, p<0.03\right)$ and axotomy $\left(F_{(1)}=157.7, p<\right.$ $0.0001)$. No significant effect of sex was observed $\left(F_{(1)}=2.95, p>\right.$ 0.1 ), a result that probably reflects the similar responses of males and females to both treatments (Fig. $2 A$ ). There was no significant interaction between treatment and axotomy $(p>0.3)$, suggesting that both the axotomized and the intact sides of N. IX-X were affected by DHT treatment. The number of cells in the intact side of males and females is very similar to values reported previously (Robertson et al., 1994) for the the number of axons in the IX-X nerve, suggesting that axotomy does not affect cell numbers on the contralateral intact side.

Compared to the corresponding intact side (Fig. 2B), the number of cells in the axotomized side was significantly smaller in untreated females $(p<0.01, n=4)$, untreated males $(p<0.01$, $n=4)$, and DHT-treated females $(p<0.01, n=4)$ and males $(p<0.05, n=4)$. This result confirms the observation of axotomy-induced cell death in N. IX-X (Fig. 1).

One potential problem with this analysis is that androgen treatment or axotomy might alter the size of cell nuclei and lead to a sampling error by affecting the probability that a cell would be counted in N. IX-X. To examine this question, the nuclear diameter was determined for 20 neurons per side from each experimental animal in all treatment groups ( $n=4$ per group). In untreated gonadectomized males, the mean nuclear diameter on the intact side was $6.0 \pm 0.5$ (mean $\pm \mathrm{SD}$ ), and on the axotomized side was $6.2 \pm 0.5$. In DHT-treated, gonadectomized males, values for the intact and axotomized sides were $6.3 \pm 0.7$ and $6.5 \pm 0.5$, respectively. In untreated gonadectomized females, values were $6.0 \pm 0.3$ (intact) and $6.2 \pm 0.2$ (axotomized). In DHT-treated females, values were $6.7 \pm 0.9$ (intact) and $7.4 \pm 1$ (axotomized). None of these comparisons (intact vs axotomized or untreated vs DHT-treated) was significantly different $(p>0.17$ for all). We conclude that effects on nuclear size did not contribute to cell counts in this study.

To determine whether endogenous androgens also affect survival in N. IX-X, gonads were left intact in a group of axotomized males (Fig. 2C). In these animals, the proportion of cells remaining in the axotomized N. IX-X, relative to number of cells in the intact side, was similar to DHT-treated males and significantly higher than in untreated males ( $p<0.05, n=4$ in all groups). The nuclear diameter in nongonadectomized males was $6.9 \pm 0.8$ in both intact and axotomized sides. The number of cells on the intact side of gonadectomized males $(377 \pm 40)$ did not differ from the number in intact males $(354 \pm 37)$, suggesting that gonadectomy, by itself, did not cause cell loss in N. IX-X. These results suggest that endogenous androgens can mitigate axotomyinduced cell death. 


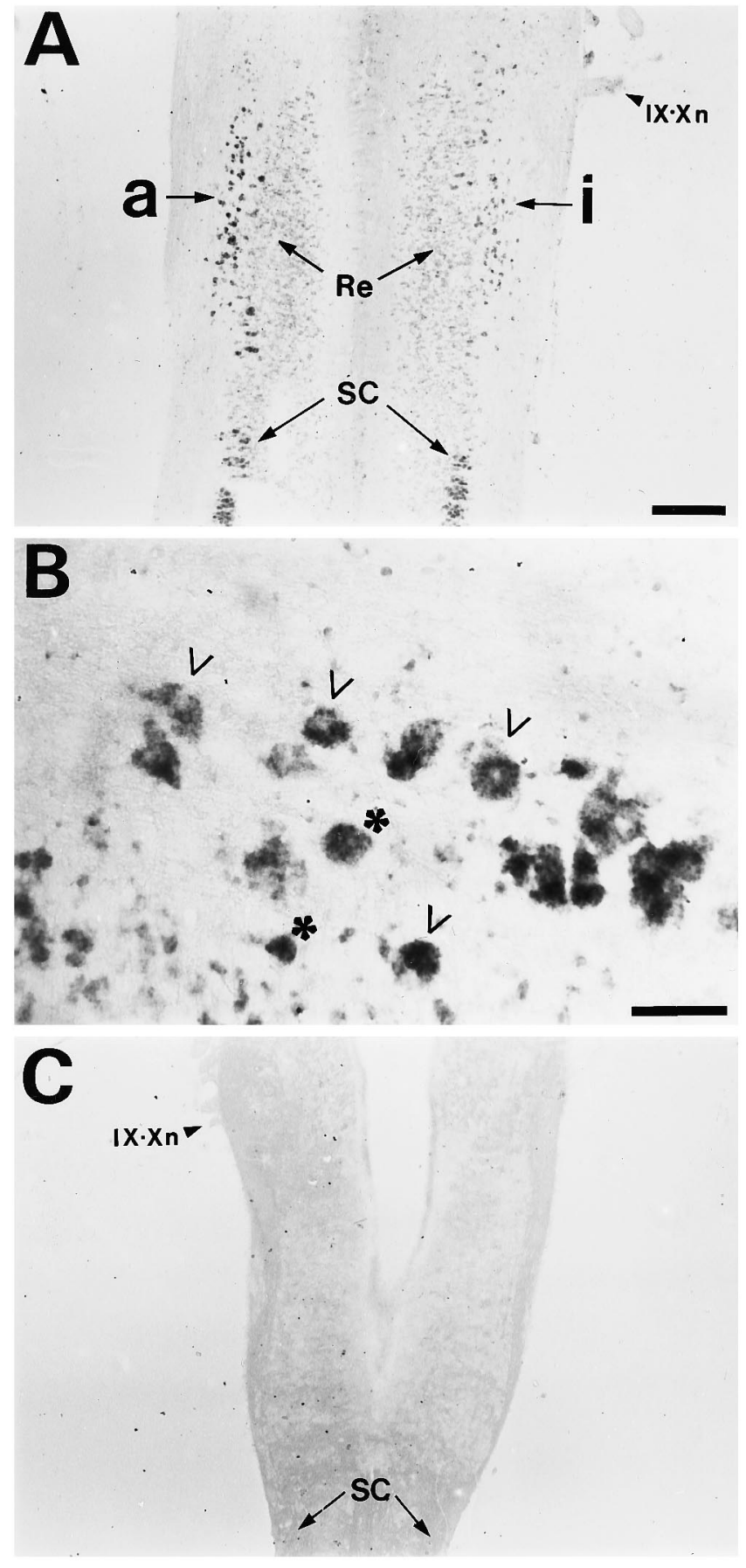

Figure 3. In situ hybridization signals with the $\mathrm{AR}$ probe in the brainstem of $X$. laevis 1 month after nerve section. $A$, Increases in in situ hybridization signals were found in the axotomized $(a) \mathrm{N}$. IX-X as compared to the intact side $(i)$. The intensity of hydridization in cells of the adjacent reticular formation $(R e)$ or motor neurons of the spinal cord $(S C)$ does not change after axotomy. The horizontal section at the level of the brainstem shows the root of the IX-X nerve $(I X-X n)$. B, A higher magnification of in situ hybridization signals in the axotomized N. IX-X of an untreated animal. Cells with unstained nucleus and cytoplasmic labeling $(V)$ were counted, whereas cytoplasmic profiles were not $(*)$. $C$, No hybridization was observed with sense probe. The horizontal section at the level of the brainstem and spinal cord $(S C)$ shows the root of the IX-X nerve $(I X-X n)$. Scale bars: $A, C, 180 \mu \mathrm{m} ; B, 25 \mu \mathrm{m}$.
UNTREATED

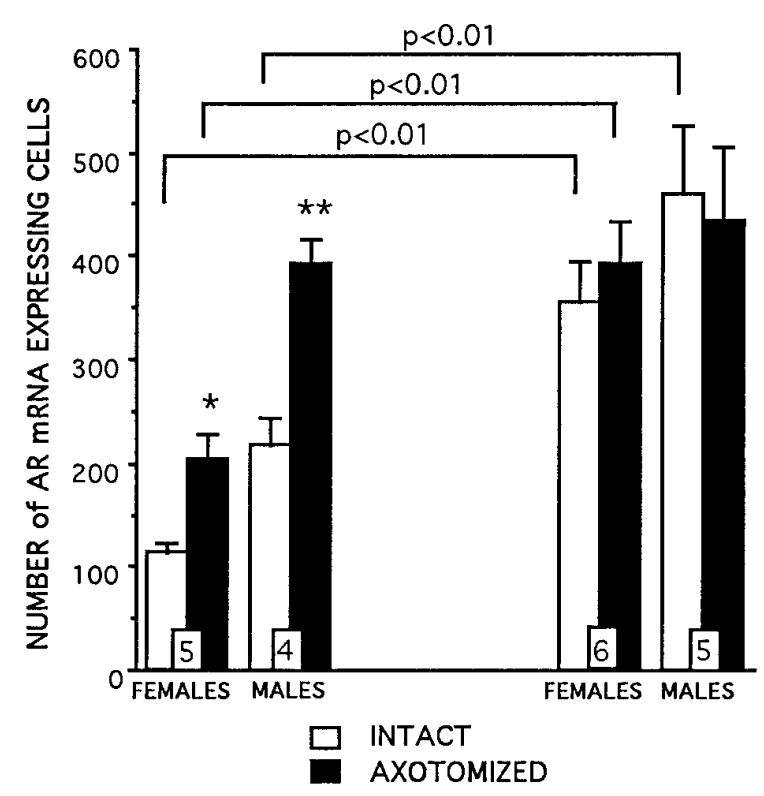

Figure 4. Number of AR mRNA-expressing cells (mean \pm SEM; $n=$ number of animals within histogram bars) in the intact (white) and axotomized (black) N. IX-X of untreated and DHT-treated animals 1 month after axotomy. Asterisks indicate significant differences between intact and axotomized sides $\left({ }^{*} p<0.05,{ }^{*} p<0.01\right)$. Brackets with significance information show differences between untreated and DHT-treated groups. In untreated animals, more AR mRNA-expressing cells were found in the axotomized side than in the intact side. The number of AR mRNA-expressing cells was significantly higher in both intact and axotomized sides of DHT-treated juveniles than the respective sides of untreated juveniles. The number of AR mRNA-expressing cells in the intact side of DHT-treated males was significantly higher than in untreated males.

\section{Effect of denervation and DHT treatment on AR mRNA-expressing cells 1 month after axotomy}

Having established that axotomy induces cell death in N. IX-X and that androgen mitigates cell loss, we next determined whether effects of axotomy and of hormone treatment are accompanied by changes in the expression of the AR gene. We examined both the 5 month time point described above and an earlier time point, 1 month after axotomy.

In untreated gonadectomized animals, section of the laryngeal nerve for 1 month produced an increase in the in situ hybridization signals detected with the AR probe in the cytoplasm of cells in $\mathrm{N}$. IX-X compared to signals in the intact side (Fig. $3 A$ ). No differences in in situ hybridization signals were found in cells of the adjacent reticular formation or in motor neurons of the spinal cord (Fig. 3A). This result suggests that axotomy specifically increases AR mRNA expression in cells of N. IX-X. In addition, the number of AR mRNA-expressing cells is affected by axotomy.

An ANOVA revealed significant main effects of axotomy (axotomized vs intact; $\left.F_{(1)}=25.4, p<0.0001\right)$, DHT treatment (untreated vs DHT-treated, $\left.F_{(1)}=17.73, p<0.007\right)$, and $\operatorname{sex}\left(F_{(1)}\right.$ $=6.07, p<0.02$ ). One month after axotomy (Fig. 4), the number of AR mRNA-expressing cells in the axotomized N. IX-X of untreated, gonadectomized females and males was 1.8-fold higher than the number in the intact side $(p<0.05, n=5$ in untreated females; $p<0.01, n=4$ in untreated males). Thus axotomy, by itself, increases AR mRNA expression.

In addition, ANOVA revealed a significant interaction between 


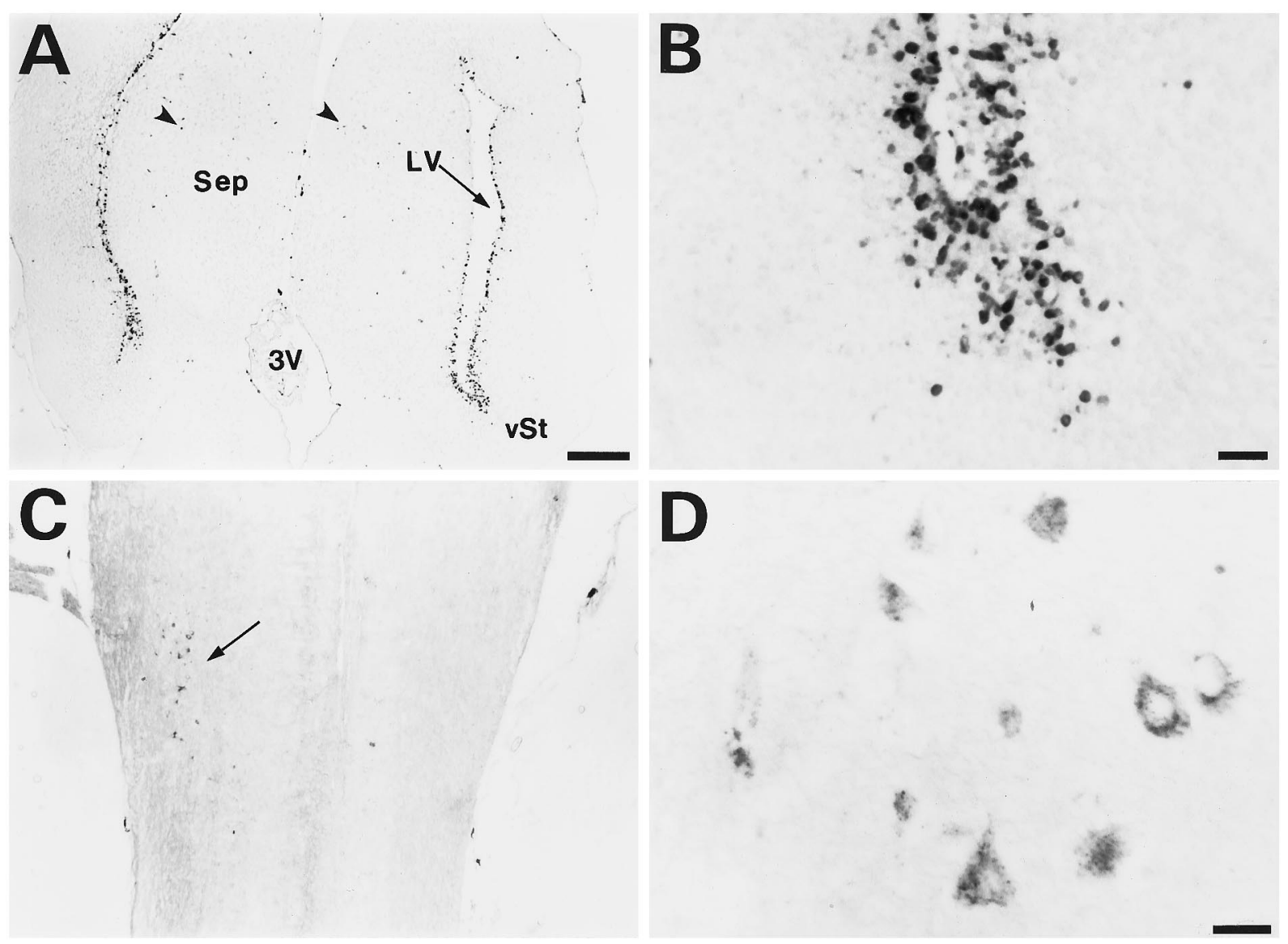

Figure 5. Cell proliferation in the CNS of juvenile frogs. $A$, Bromodeoxyuridine labeling was found in cells of the ependymal layer of the lateral ventricle ( $L V$ ) within the telencephalon and in cells in the ventral striatum $(v S t)$ and septum (Sep; arrowheads). $3 V$, Third ventricle. B, A higher magnification of bromodeoxyuride-labeled cell nuclei in the ventral striatum. $C$, In the same animals, after DHT treatment for 1 month, N. IX-X was back-labeled with HRP (arrow). $D$, A higher magnification of $C$ shows no bromodeoxyuridine labeling in HRP-back-labeled motor neurons of N. IX-X. Scale bars: $A, C, 140 \mu \mathrm{m} ; B$, $10 \mu \mathrm{m} ; D, 10.7 \mu \mathrm{m}$.

treatment and axotomy $(p<0.0002)$. In contrast to gonadectomized juveniles, there was no significant difference in number of AR mRNA-expressing cells between intact and axotomized sides of DHT-treated gonadectomized juveniles $(p>0.1, n=5$ males, $n=6$ females; Fig. 4). This effect is the result of a DHT-induced increase in number of AR mRNA-expressing cells. There was no significant two-way interaction between sex and axotomy $(p>$ $0.9)$ or sex and DHT treatment $(p>0.4)$. We conclude that there is no sexual dimorphism in response to axotomy and DHT treatment.

Finally, there is a significant three-way interaction between axotomy, DHT treatment, and sex $(p<0.009)$. Both the intact and the axotomized N. IX-X of DHT-treated females had significantly more AR mRNA-expressing cells than the respective sides of untreated females (both comparisons, $p<0.01$ ). In DHT-treated males, the number of AR mRNA-expressing cells in the intact side was significantly higher than in untreated males $(p<0.01)$, but there was no significant effect of DHT treatment on the number of cells that express AR mRNA in the axotomized N. IX-X $(p>0.05)$. Because in females DHT induced similar increases in number of AR mRNA-expressing cells in both intact and axotomized sides, we conclude that increases are independent of axonal state and contact with muscle.

\section{Cell proliferation in the CNS of juvenile animals}

We next determined whether the increases in the number of AR mRNA-expressing cells seen 1 month after denervation or DHTtreatment of juvenile animals is the result of an induction of cell proliferation. One month after treatment, bromodeoxyuridine labeling was observed in the telencephalon of untreated and DHT-treated animals (Fig. 5A). This result indicates that bromodeoxyuridine effectively reached the CNS and labeled dividing cells. Cells with immunoreactive nuclei were found in the ependymal layer of the telencephalic ventricles and in cells of the ventral striatum and the septum (Fig. $5 B$ ) but not in either intact or axotomized N. IX-X of untreated or DHT-treated animals (Fig. $5 C)$. No HRP labeled motor neurons in N. IX-X were labeled with bromodeoxyuridine (Fig. $5 D$ ). We conclude that the increased number of AR mRNA-expressing cells observed in $\mathrm{N}$. IX-X 1 month after axotomy or DHT treatment does not result from cell proliferation.

\section{Effects of axotomy and DHT treatment on AR mRNA- expressing cells of $\mathbf{N}$. IX-X after prolonged axotomy}

We next examined AR mRNA expression 5 months after axotomy, a time point at which cell death is occurring. Fewer AR mRNA-expressing cells were present on the axotomized than on the intact side (compare left side of Fig. $6 A$ to Fig. $6 B$ ). 
An ANOVA revealed significant main effects of axotomy $\left(F_{(1)}\right.$ $=79.13, p<0.0001)$, DHT treatment $\left(F_{(1)}=14.31, p<0.01\right)$, and $\operatorname{sex}\left(F_{(1)}=5.67, p<0.05\right)$. Axotomy reduces the number of AR mRNA-expressing cells in N. IX-X. For example, in untreated gonadectomized females and males the ratio of $\mathrm{AR}$ mRNA-expressing cells in the axotomized to the intact contralateral side $(\times 100)$ was $26.3 \pm 5(n=3)$ and $33.3 \pm 4(n=3)$, respectively (Fig. $7 A$ ). A significant difference (Fig. $7 B$ ) in number of AR mRNA-expressing cells was found between the axotomized and intact contralateral side of untreated females $(p<0.01, n=$ $3)$, males $(p<0.05, n=3)$, and DHT-treated males $(p<0.05$, $n=3)$; in DHT-treated females, the difference between intact and axotomized sides did not attain significance $(p=0.1, n=3)$. The effects of axotomy are independent of hormone treatment $(p>$ 0.7 ); thus, axotomy produces a decrease in the number of AR mRNA-expressing cells in both untreated and DHT-treated juveniles.

DHT treatment increases the number of AR mRNA-expressing cells. For example, treatment with DHT increases the ratio $\times 100$ of AR mRNA-expressing cells in the axotomized to intact side to $51.6 \pm 4(n=3)$ in females and $56.4 \pm 5(n=3)$ in males (Fig. $7 A$ ). These values differ significantly from the survival percentage in untreated animals $(p<0.05)$. We conclude that more AR mRNA-expressing cells remain in N. IX-X after axotomy if animals are treated with DHT.

The magnitude of the effect of axotomy and DHT treatment on AR mRNA-expressing cells is similar to the effect on all cells in the nucleus (Fig. 2). For all groups, there are fewer AR mRNAexpressing cells in N. IX-X of females than of males. There is no significant interaction between sex and DHT treatment $(p>0.02)$ or axotomy $(p>0.03)$. We conclude that prolonged axotomy decreases the number of AR mRNA-expressing cells in N. IX-X of both males and females and that DHT treatment mitigates this effect in both sexes.

\section{DISCUSSION}

\section{Cell death induced by axotomy in N. IX-X: a useful model system for trophic factors}

Motor neurons of developing animals are especially sensitive to injury and, unlike adult cells, will often die after axotomy. This dramatic effect makes injury-induced death a model for evaluating the effects of suspected trophic factors (Li et al., 1994). By 5 months after section of the laryngeal nerve, cells in N. IX-X of juvenile $X$. laevis undergo cell death. Some degenerating cells in $\mathrm{N}$. IX-X present a swollen appearance, and some are pyknotic, both classical signs of injury induced necrosis in motor neurons (Lieberman, 1971). In addition, the total number of cells in the nucleus is reduced after axotomy, a result consistent with injuryinduced cell death. Cell proliferation can accompany injury of the CNS (Pérez and Perentes, 1995; Pérez et al., 1995) and might contribute to some of the changes in the number of cells in $\mathrm{N}$. IX-X observed in this study. However, using bromodeoxyuridine we saw no significant effects of axotomy on cell proliferation in $\mathrm{N}$. IX-X of juvenile animals. These results establish the laryngeal motor nucleus as potentially useful in evaluation of trophic agents.

\section{Trophic effects of androgens on N. IX-X}

Cells in N. IX-X express high levels of androgen receptor (Kelley, 1981; Pérez et al., 1996), suggesting that this system might also be useful in determining whether the hormone has a trophic function. Whereas only $37 \%$ of the cells in the N. IX-X survived 5 months of axotomy in untreated frogs, $60 \%$ survived after DHT

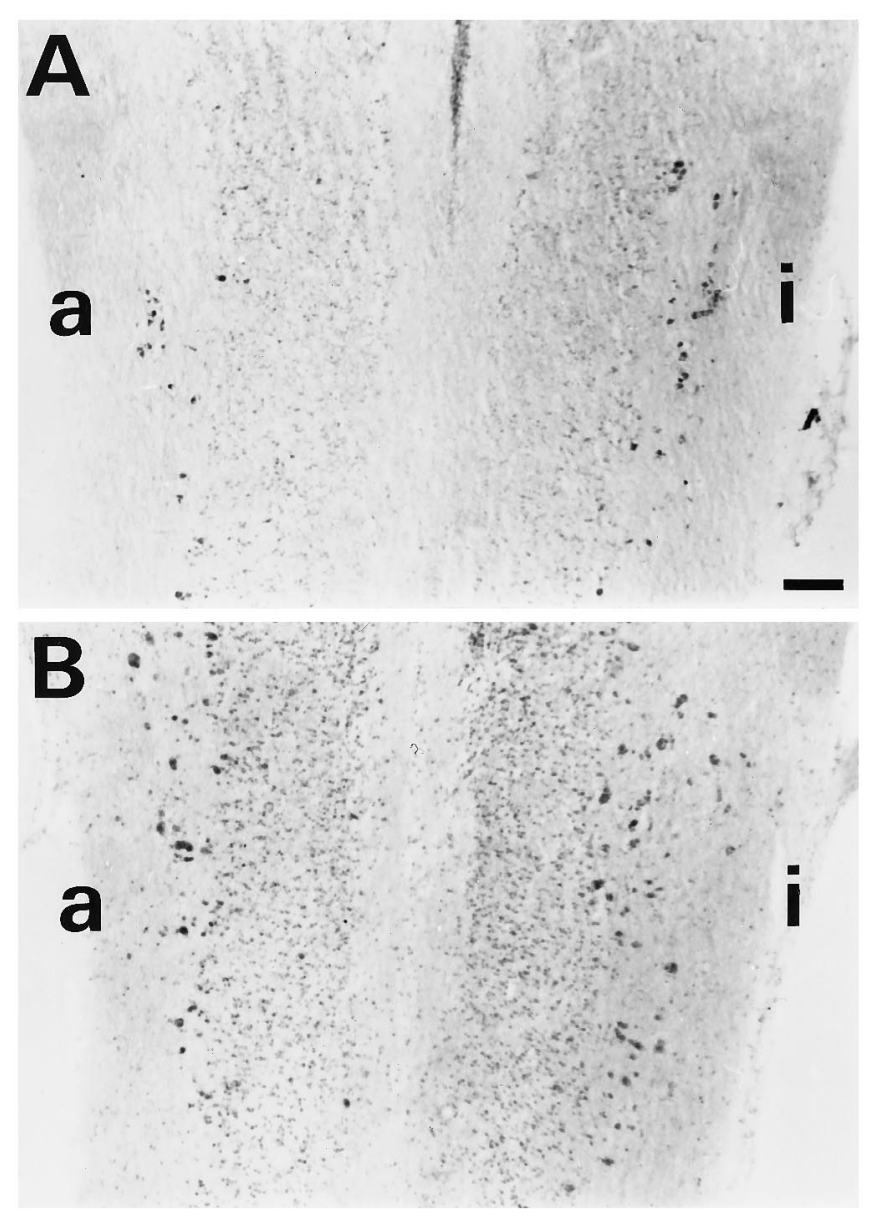

Figure 6. Hybridization of the AR probe to cells in the brainstem of an untreated male $(A)$ and a DHT-treated male $(B) 5$ months after axotomy. In untreated animals, fewer AR mRNA-expressing cells were present in the axotomized N. IX-X $(a)$ than in the intact side $(i)$. DHT-treated animals had significantly more AR mRNA-expressing cells in the axotomized side than did untreated animals. Scale bar, $75 \mu \mathrm{m}$.

treatment. Although castration itself appeared to have no effect on the number of neurons in N. IX-X of males, the survival of N. IX-X cells was less than that seen in males with testes. The magnitude of DHT-enhanced survival in gonadectomized males was comparable to that in intact males, suggesting that effects seen here reflect physiological rather than pharmacological effects of androgens. We conclude that androgens are trophic hormones that either mitigate or delay the cell loss induced by axotomy in N. IX-X.

Counts of cresyl violet-stained cells in N. IX-X of P.M.1 juveniles indicate that DHT for 5 months increases cell number in the nucleus, even on the intact side. At early juvenile stages, N. IX-X in untreated males and females consists entirely of laryngeal motor neurons (the number of cresyl violet-stained cells in the nucleus matches the number of laryngeal axons). At P.M.0, laryngeal axon numbers in both sexes are greater than they will be in adults; females attain adult values by P.M.2 and males by P.M.5 (Robertson et al., 1994). Thus, mitigation of ontogenetic cell death may be contributing to DHT-induced increases in N. IX-X cell numbers in the intact side.

Our results are consistent with previous studies showing that androgens ameliorate cell death induced by axotomy in the rat facial and hypoglossal nuclei (Yu, 1989). In hamster facial motor 

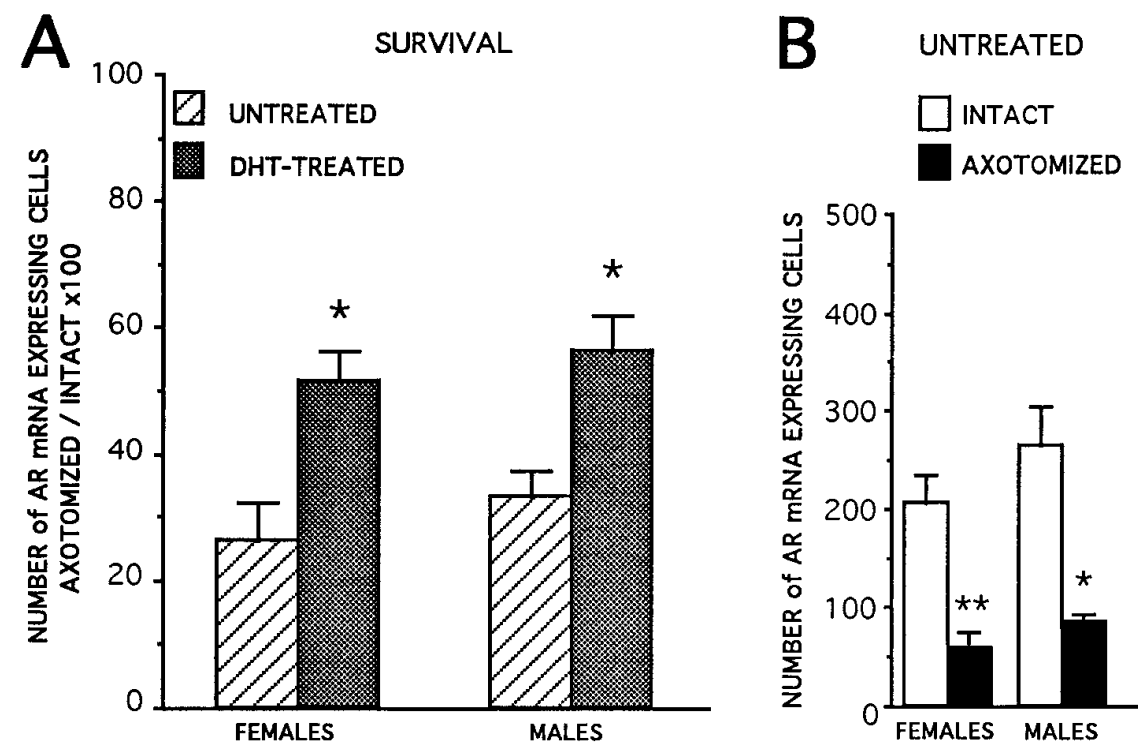

\section{DHT-TREATED}

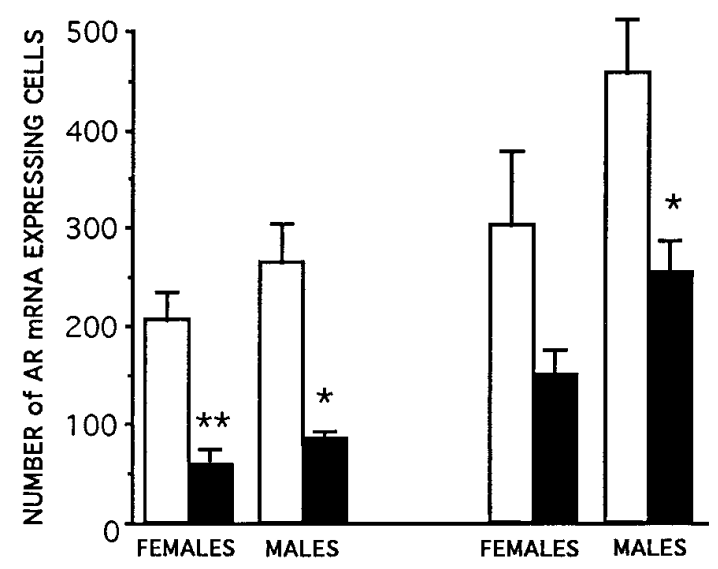

Figure 7. AR mRNA-expressing cells 5 months after axotomy. $A$, DHT treatment resulted in significantly more AR mRNA-expressing cells in the axotomized N. IX-X than were seen in untreated animals (mean \pm SEM; $n=3$ animals/group). $B$, Number of AR mRNA-expressing cells in N. IX-X of untreated and DHT-treated animals (mean \pm SEM; $n=3$ animals/group). Asterisks represent significant differences between intact and axotomized sides $\left({ }^{*} p<0.05 ;{ }^{* *} p<0.01\right)$. Axotomy for 5 months caused significant decrease in number of AR mRNA-expressing cells in the axotomized N. IX-X of untreated males and females and DHT-treated males.

neurons testosterone enhances axonal regeneration after nerve crush (Kujawa et al., 1991). Kennedy's disease (associated with loss of AR function) is commonly thought to result from motor neuron death (Harding et al., 1982). Taken together, these results suggest a trophic function for androgen in motor nuclei.

\section{Mechanisms for androgen-induced survival of cells in N. IX-X}

Regulation of androgen receptor expression is a candidate mechanism for androgen-induced survival of cells in N. IX-X. In gonadectomized males and females, the number of AR mRNAexpressing cells in N. IX-X 1 month after axotomy was approximately twice that on the intact side. Because the number of AR mRNA-expressing cells on the intact side is the same as the number obtained in a previous study of non-axotomized males at this stage, we ruled out an effect of axotomy in the intact side (Pérez et al., 1996). The increased signals with the AR probe was seen only in N. IX-X and not in adjacent cells of the reticular formation or other motor neurons. Furthermore, the increase of AR mRNA-expressing cells is not attributable to injury-induced cell proliferation. We conclude that after 1 month, increased AR mRNA expression occurs in cells of N. IX-X specifically as a response to axotomy. Motor neurons in N. IX-X bind radioactive androgens; thus, the AR mRNA present in these cells is translated into functional protein (Kelley et al., 1975; Kelley, 1980, 1981; Pérez et al., 1996). Because an increase in AR mRNA expression in the axotomized N. IX-X is followed by DHT-mediated cell rescue, we suggest that increased AR transcription is a survival mechanism that leads to increased levels of receptor and allows injured cells to more effectively bind circulating androgens.

Although the increase in AR mRNA expression observed shortly after axotomy may be a specific result of the activation of cell programs essential for survival, it could represent, instead, a more general component of injury-induced increases in transcription. Axotomy induces a series of changes in gene expression. For instance, tubulin, low-affinity NGF receptor, and GAP-43 synthe- sis are enhanced by axotomy, whereas expression of neurofilament and choline acetyltransferase decreases (Hoffman et al., 1987; Ernfors et al., 1989; Brunello et al., 1990; Armstrong et al., 1991; Koliatsos et al., 1991; Chong et al., 1994). The pattern of responses to axotomy suggests repression of genes related to specialized functions such as neurotransmission and enhanced transcription of genes related to survival and axonal regrowth. Although we have demonstrated a transcriptional regulation of the AR, we do not rule out additional levels of regulation (translational and/or post-translational).

The results described here differ from previous reports in a comparable neuromuscular system of rats, the spinal nucleus of the bulbocavernosus (SNB). In this system, axotomy induces death of SNB motor neurons up to 2 weeks after birth (Lubischer and Arnold, 1995a); axotomy during this period also results in a transient decrease in androgen receptor immunoreactivity in SNB cells (Lubischer and Arnold, 1995b). A salient difference between juvenile SNB motor neurons in rats and juvenile laryngeal motor neurons in Xenopus is that androgen has no effect on the survival of SNB cells (Lubischer and Arnold, 1995a), whereas androgen does promote cell survival in laryngeal cells (this report). Differences in AR regulation in these two systems lend some support to the hypothesis that upregulation of AR mRNA by androgen and axotomy contributes to its trophic actions.

DHT treatment for 1 month increases the number of AR mRNA-expressing cells in N. IX-X. This result is consistent with previous data suggesting that DHT regulates AR in X. laevis brain (Pérez et al., 1996) and with increases in AR immunoreactivity and mRNA in the brain of castrated rats after androgen treatment (Menard and Harlan, 1993; Kerr et al., 1995). Because an increase in the number of AR mRNA-expressing cells is not accompanied by cell proliferation, the result suggests an upregulation of AR mRNA transcription. In females, DHT upregulates AR mRNA expression on the axotomized side, whereas in males axotomy itself may have already induced the maximum number of cells able 
to express AR, and DHT has no further effect. This result suggests a limit to the number of cells that can express AR mRNA in N. IX-X, a limit represented by the number achieved after axotomy in males and by the combined effect of axotomy and DHT treatment in females. The DHT-induced increase in number of AR mRNA-expressing cells was similar in the axotomized and intact sides, suggesting that injured cells can respond to androgen. A second conclusion is that regulation of AR expression in cells of $\mathrm{N}$. IX-X does not require contact with muscle.

\section{Prolonged axotomy: DHT treatment and AR mRNA-expressing cells}

Five months after axotomy, there is a dramatic loss $(60 \%)$ of cells in N. IX-X, and DHT treatment rescues some of these cells $(40 \%$ loss). Nucleus IX-X of juveniles is heterogeneous, containing motor neurons that express AR mRNA and motor neurons that do not (Pérez et al., 1996). Does DHT treatment specifically maintain AR mRNA-expressing cells? Because the number of AR mRNA-expressing cells in the nucleus increases after axotomy or DHT treatment without a concomitant proliferation of cells, ARnegative cells can become AR-positive. Expression of AR mRNA thus does not define a specific class of N. IX-X cells. For this reason, we do not know whether DHT specifically rescues AR mRNA-expressing cells. We can only conclude that, after prolonged axotomy, more cells express AR mRNA in N. IX-X if treated with DHT. In addition, we cannot rule out the possibility that the early upregulation of AR mRNA-expressing cells, evident 1 month after axotomy, contributes to the greater number of AR mRNA-expressing cells in DHT-treated animals 5 months after axotomy.

Here we show that androgen can partially compensate the motor neuron for loss of its muscle target. We have shown previously that exposure to exogenous androgen can compensate the muscle for loss of innervation (Tobias et al., 1993). The common, trophic effect of androgen on the neuromuscular partners could be attributable to a shared survival program. Alternatively, androgen may access cell-specific survival programs involving, for example, distinct growth factors or receptors. In either case, elucidation of androgen-inducible genes that participate in neuronal survival may yield useful insights into the process of neural repair after injury.

\section{REFERENCES}

Abercrombie M (1946) Estimation of nuclear population from microtome sections. Anat Rec 94:239-247.

Armstrong DM, Brady R, Hersh LB, Hayes RC, Wiley RG (1991) Expression of choline acetyltransferase and nerve growth factor receptor within hypoglossal motor neurons following nerve injury. J Comp Neurol 304:596-607.

Breedlove SM (1992) Sexual dimorphism in the vertebrate nervous system. J Neurosci 12:4133-4142.

Brunello N, Reynolds M, Wrathall JR, Mocchetti I (1990) Increased nerve growth factor receptor mRNA in contused rat spinal cord. Neurosci Lett 118:238-240.

Conover JC, Erickson JT, Katz DM, Bianchi LM, Poueymirou WT, McClain J, Pan L, Helgren M, Ip NY, Boland P, Friedman B, Wiegand S, Vejsada R, Kato AC, DeChiara TM, Yancopuoulus GD (1995) Neuronal deficits, not involving motor neuron, in mice lacking BDNF and/or NT4. Nature 375:235-238.

Chong MS, Reynolds ML, Irwin N, Coggeshall RE, Emson PC, Benowitz LI, Woolf CJ (1994) GAP-43 expression in primary sensory neurons following central axotomy. J Neurosci 14:4375-4384.

Ernfors P, Henschen A, Olson L, Persson H (1989) Expression of nerve growth factor receptor mRNA is developmentally regulated and in- creased after axotomy in rat spinal cord motor neurons. Neuron $1605-1613$

Ernfors P, Lee K-F, Jaenisch R (1994) Lack of neurotrophin-3 leads to deficiencies in the peripheral nervous system and loss of limb propioceptive afferents. Cell 77:503-512.

Fischer LM, Catz D, Kelley DB (1993) An androgen receptor mRNA isoform associated with hormone induced cell proliferation. Proc Natl Acad Sci USA 90:8254-8258.

Harding AE, Thomas PK, Baraitser M, Bradbury PG, Morgan-Hughes JA, Ponsford JR (1982) X-linked recessive neuronopathy: a report of ten cases. J Neurol Neurosurg Psychiatry 45:1012-1019.

He WW, Fischer LM, Sun S, Bilhartz DL, Zhu X, Young CY-F, Kelley DB, Tindall DJ (1990) Molecular cloning of androgen receptors from divergent species with a polymerase chain reaction technique: complete cDNA sequence of the mouse androgen receptor and isolation of androgen receptor cDNA probes from dog, guinea pig and clawded frog. Biochem Biophys Res Commun 171:697-704.

Hoffman PN, Cleveland DW, Griffin JW, Landes PW, Cowan NJ, Price DL (1987) Neurofilament gene expression: a major determinant of axonal caliber. Proc Natl Acad Sci USA 84:3472-3476.

Kelley DB (1980) Auditory and vocal nuclei in the frog brain concentrate sex hormones. Science 207:553-555.

Kelley DB (1981) Locations of androgen-concentrating cells in the brain of Xenopus laevis: autoradiography with ${ }^{3} \mathrm{H}$-dihydrotestosterone. J Comp Neurol 199:221-231.

Kelley DB (1996) Sexual differentiation in X. laevis. In: The biology of Xenopus (Tinsley R, Kobel H, eds), pp 143-176. New York: Oxford UP.

Kelley DB, Morrell JI, Pfaff DW (1975) Autoradiographic localization of hormone-concentrating cells in the brain of an amphibian, Xenopus laevis: testosterone. J Comp Neurol 164:47-61.

Kelley D, Sassoon D, Segil N, Scudder M (1989) Development and hormone regulation of androgen receptor levels in the sexually dimorphic larynx of Xenopus laevis. Dev Biol 131:111-118.

Kerr JE, Allore RJ, Beck SG, Handa RJ (1995) Distribution and hormonal regulation of androgen receptor (AR) and AR messenger ribonucleic acid in the rat hippocampus. Endocrinology 136:3213-3221.

Klein R, Smeyne R, Wursy W, Long L, Auerbach B, Joyner A, Barbacid M (1993) Targeted disruption of the trkB neurotrophin receptor gene results in nervous system lesions and neonatal death. Cell 75:113-22.

Kujawa KA, Jones KJ (1995) Trophic actions of gonadal steroids on neuronal functioning normally and folowing injury. In: Advances in neuronal science, Vol 2, pp 131-152. Greenwich, CT: JAI.

Kujawa KA, Emeric E, Jones KJ (1991) Testosterone differentially regulates the regenerative properties of injured hamster facial motorneurons. J Neurosci 11:3898-3906.

Koliatsos VE, Crawford TO, Price DL (1991) Axotomy induces nerve growth factor receptor immunoreactivity in spinal motor neurons. Brain Res 549:297-304.

La Spada AR, Wilson EM, Lubahn DB, Harding AE, Fischbeck KH (1991) Androgen receptor gene mutations in X-linked spinal and bulbar muscular atrophy. Nature 352:77-79.

Levi-Montalcini R, Booker B (1960) Destruction of the sympathetic ganglia in mammals by an antiserum to nerve growth factor protein. Proc Natl Acad Sci USA 46:384-391.

Lewin G, Barde Y (1996) Physiology of the neurotropins. Annu Rev Neurosci 19:289-317.

Li L, Oppenheim R, Lei M, Houenou L (1994) Neurotrophic agents prevent motoneuron death following sciatic nerve section in the neonatal mouse. J Neurobiol 25:759-766.

Lieberman AR (1971) The axon reaction: a review of the principal features of perikaryal responses to injury. Int Rev Neurobiol 14:49-124.

Liu X, Ernfords P, Wu H, Jaenisch R (1995) Sensory but not motor neurons deficits in mice lacking NT4 and BDNF. Nature 375:238-241.

Llewellyn-Smith IJ, Pilowsky P, Minson JB (1992) Retrograde tracers for light and electron microscopy. In: Experimental neuroanatomy: a practical approach, pp 31-58. Oxford: IRL.

Lubischer JL, Arnold AP (1995a) Axotomy of developing rat spinal motorneurons: cell survival, soma size, muscle recovery, and the influence of testosterone. J Neurobiol 26:225-240.

Lubischer JL, Arnold AP (1995b) Axotomy transiently down-regulates androgen receptors in motorneurons of the spinal nucleus of the bulbocavernosus. Brain Res 694:61-68.

MacLean HE, Choi W-T, Rekaris G, Warne GL, Zajac JD (1995) Abnormal androgen receptor binding affinity in subjects with Kennedy's 
disease (spinal and bulbar muscular atrophy). J Clin Endocrinol Metab 80:508-516.

Menard CS, Harlan RE (1993) Up-regulation of androgen receptor immunoreactivity in the rat brain by androgenic-anabolic steroids. Brain Res 622:226-236.

Nordeen E, Nordeen K, Sengelaub D, Arnold A (1985) Androgens prevent normally occurring cell death in a sexually dimorphic spinal nucleus. Science 229:671-673.

Oppenheim RW, Houenou LJ, Johnson JE, Lin L-F H, Linxi L, Lo AC, Newsome AL, Prevette DM, Wang S (1995) Developing motor neurons rescued from programmed and axotomy-induced cell death by GDNF. Nature 373:344-346.

Pérez J, Hoyer D (1995) Co-expression of somatostatin SSTR-3 and SSTR-4 receptor messenger RNAs in the rat brain. Neuroscience 64:241-253.

Pérez J, Perentes E (1995) Light-induced retinopathy in the albino rat in long-term studies: an immunohistochemical and quantitative approach. Exp Toxicol Pathol 46:229-235.

Pérez J, Vezzani A, Civenni G, Tutka P, Rizzi M, Schüpbach E and Hoyer D (1995) Functional effects of D-Phe-c[Cys-Tyr-D-Trp-Lys-Val-Cys]Trp- $\mathrm{NH}_{2}$ and differential changes in somatostatin receptor messenger
RNAs, binding sites and somatostatin release in kainic-acid treated rats Neuroscience 65:1087-1097.

Pérez J, Cohen M, Kelley DB (1996) Androgen receptor mRNA expression in Xenopus laevis CNS: sexual dimorphism and regulation in the laryngeal motor nucleus. J Neurobiol 30:556-568.

Robertson JC, Watson JT, Kelley DB (1994) Androgen directs sexual differentiation of laryngeal innervation in developing Xenopus laevis. J Neurobiol 25:1625-1636.

Ross CA (1995) When more is less: pathogenesis of glutamine repeat neurodegenerative diseases. Neuron 15:493-496.

Simpson HB, Tobias ML, Kelley DB (1986) Origin and identification of fibers in the cranial nerve IX-X complex of Xenopus laevis: Lucifer Yellow backfills in vitro. J Comp Neurol 244:430-444.

Tobias ML, Marin ML, Kelley DB (1991) Development of functional sex differences in the larynx of Xenopus laevis. Dev Biol 147:251-259.

Tobias ML, Marin ML, Kelley DB (1993) The roles of sex, innervation and androgen in laryngeal muscle of Xenopus laevis. J Neurosci 13:324-333.

$\mathrm{Yu}$ W-HA (1989) Administration of testosterone attenuates neuronal loss following axotomy in the brain-stem motor nuclei of female rats. J Neurosci 9:3908-3914. 